\title{
Cytogenetics of Amaryllidaceae species: heterochromatin evolution in different ploidy levels
}

\author{
W. J. P. Felix • L. P. Felix • N. F. Melo • \\ J. H. A. Dutilh $\cdot$ R. Carvalho
}

Received: 14 August 2010/Accepted: 28 January 2011/Published online: 25 February 2011

(C) Springer-Verlag 2011

\begin{abstract}
Species belonging to the Amaryllidaceae (Zephyranthes and Habranthus) were analyzed by banding with chromomycin A3 (CMA)/4,6-diamidino-2-phenylindole (DAPI) fluorochromes. The patterns of bands were studied in seven species of Zephyranthes Herb. and one of Habranthus Herb. Subterminal and interstitial DAPI+ bands were observed in $Z$. robusta $2 \mathrm{n}=12$ and $Z$. brachyandra $2 \mathrm{n}=24$. Other species showed no AT-rich heterochromatin. In species with $2 \mathrm{n}=12$, CMA+ bands were observed on one chromosome pair of $Z$. robusta and Zephyranthes sp., while in Z. sylvatica an additional small terminal band in the fifth chromosome pair was observed. $Z$. rosea and $Z$. grandiflora presented with $2 n=24$ and had four CMA+ bands, while in Z. brachyandra, with
\end{abstract}

\footnotetext{
W. J. P. Felix

Mestrado em Melhoramento Genético de Plantas, Departamento de Agronomia, UFRPE, Recife, PE, Brazil e-mail: winstonpessoa@yahoo.com.br

L. P. Felix

Laboratório de Citogenética Vegetal, Departamento de Fitotecnia, Universidade Federal da Paraíba, Areia, PB, Brazil e-mail: lpfelix@hotmail.com

N. F. Melo

Laboratório de Biotecnologia, Embrapa Semi-Árido, Petrolina, PE, Brazil

e-mail: natoniel@cpatsa.embrapa.br

J. H. A. Dutilh

Departamento de Botânica, Instituto de Biologia, Universidade Estadual de Campinas, Campinas, SP, Brazil

e-mail: capitani@unicamp.br

R. Carvalho $(\bowtie)$

Laboratório de Citogenética Vegetal, Departamento de Biologia/Genética, UFRPE, Recife, PE, Brazil

e-mail: reginaldo.ufrpe@gmail.com
}

$2 \mathrm{n}=24+1 \mathrm{~B}$, there were eight interstitial dot bands and a larger terminal band in the short arm of the $\mathrm{B}$ chromosome. Z. candida with $2 \mathrm{n}=38$ presented CMA + heterochromatin blocks on the long arms of five metacentric pairs and in the short arm of one of the submetacentric pairs; in addition a terminal band was observed on the long arm of one of the homologues of a larger submetacentric pair. H. itaobinus showed a heterozygous pair revealing a strong CMA+ band in only one of the homologues, likely a nucleolus organizing region. Taxonomic implications and karyotype evolution of this group are discussed and correlated with previous data from the literature.

Keywords CMA/DAPI · Polyploidy · Chromosome . Heteromorphism $\cdot$ B chromosome

\section{Introduction}

The genus Zephyranthes Herb. comprises about 65 species of mostly Neotropical distribution (Hutchinson 1959; Judd et al. 1999) from the southern United States to southern Chile and Argentina, with 36 species reported from Brazil, some of which have great potential for ornamental use (Dutilh 2005). The genus is included in tribe Hippeastreae where three clades form subtribe Zephyranthinae subtribe. It is included in the Amaryllidaceae family and related to genus Habranthus Herb. (Meerow et al. 2007), the latter often considered a Zephyranthes synonym. For some authors Zephyranthes has flowers and erect stamens, while in Habranthus flowers and stamens are declined, although often these characteristics overlap (Arroyo 1981). In the single phylogenetic analysis that included some species of the genus, three clades were formed: one with species distributed in the southern United States and Mexico, another, along with Habranthus, formed 
by species from South America, and a third one involving species from the southern United States and South America (Meerow et al. 2000a).

Most species recognized in Habranthus present $2 \mathrm{n}=12$ or similar numbers, whereas species recognized in Zephyranthes present with $2 n=24$ or multiples of this

The members of Hippeastreae differ from the other Amaryllidaceae from South America by diploid karyotype and deletions in a set of bases in both ITS on the rDNA 45S (Meerow et al. 2000b). Zephyranthes taxonomically is a very complex genus, with poorly defined morphological boundaries between species. A chromosome record is available for 50 species out of about 65 known (Greizerstein and Naranjo 1987). Most species recognized in Habranthus present $2 \mathrm{n}=12$ or similar numbers, whereas species recognized in Zephyranthes present with $2 \mathrm{n}=24$ or multiples of this (Oliveira 2006). However, it is a very variable genus in terms of chromosome numbers, with counts from $2 \mathrm{n}=10$ in Z. seubertii (Daviña 2001) to $2 n=200$ in an interspecific horticultural hybrid (Flory and Smith 1980).

The variability in numbers is due to events of polyploidy, aneuploidy and disploidy, in addition to the presence of B chromosomes, which are frequent in the genus (Greizerstein and Naranjo 1987; Felix et al. 2008). Chromosome records on intraspecific numerical variations and B chromosomes in species such as Z. aff. mesochloa, Z. brasiliensis, Z. grandiflora, Z. chlorozolen, Z. candida, and Z. sylvatica (Raina and Khoshoo 1971; Bhattacharyya 1972; Greizerstein and Naranjo 1987; Felix et al. 2007, 2008) are well documented and indeed confirm the great numerical chromosome variability of the genus. However, the only record involving banding techniques with basespecific fluorochromes (Daviña 2001) is restricted to a single species and does not provide an overview of the structural cytological variability of the genus.

In this work seven species of Zephyranthes and one of Habranthus were analyzed by cytological banding with the chromomycin A3 (CMA) and 4,6-diamidino-2-phenylindole (DAPI) fluorochromes to further characterize the karyotypes and to increase our understanding of karyotype evolution in these species.

\section{Materials and methods}

A total of eight Amaryllidaceae species, seven of Zephyranthes and one of Habranthus, were studied. Table 1 summarizes the information about species examined, synonym, provenance (origin), karyotype formula, and chromosome number. All material was grown in pots in the experimental garden of the Plant Cytogenetics Laboratory, Centre for Agrarian Sciences, Federal University of Paraíba. The samples were deposited in the Jayme Coelho

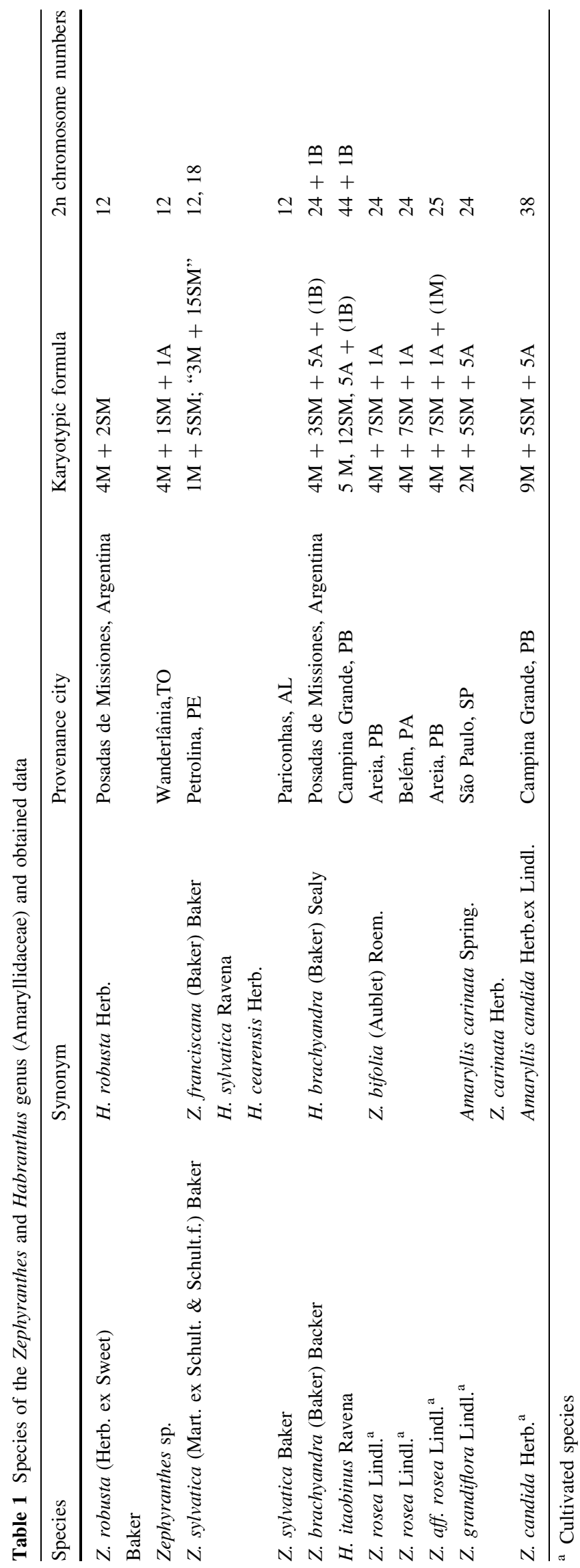


de Moraes Herbarium at the Center for Agrarian Sciences, Federal University of Paraíba, and also at the Agronomic Institute of Campinas, São Paulo.

For mitotic analysis, root tips were obtained and pretreated with 8-hydroxyquinoline $(2 \mathrm{mM})$ overnight at $10^{\circ} \mathrm{C}$, fixed in Carnoy fixative 3:1 (ethanol:acetic acid v/v) for $4 \mathrm{~h}$ at room temperature, and stored in a freezer at $-20^{\circ} \mathrm{C}$. The material was washed in distilled water and digested in an enzyme solution [2\% cellulase Onozuka (Serva)-20\% pectinase (Sigma) (w/v)] for $1 \mathrm{~h}$ at $37^{\circ} \mathrm{C}$. Next, slides were prepared via crushing in a drop of $45 \%$ acetic acid, and the cover slides were removed in liquid nitrogen. The slides were air-dried and aged for 3 days at room temperature.

The Schweizer (1976) protocol was followed with minor modifications. After the plant material was aged for 3 days, it was stained with $0.5 \mathrm{mg} / \mathrm{ml} \mathrm{CMA} \mathrm{for} 1 \mathrm{~h}$ and $2 \mu \mathrm{g} / \mathrm{ml}$ DAPI for $30 \mathrm{~min}$, then mounted with $10 \mu \mathrm{l}$ of McIlvaineglycerol $(1: 1, \mathrm{v} / \mathrm{v})$. A Leica DMRB photomicroscope equipped with ultraviolet light and Leica DC 300F video camera were used to capture the images, which were processed using Image Manager 50 software.

\section{Results}

Seven Zephyranthes species were analyzed, four of them from a native field and three cultivated as ornamentals, together with one Habranthus species (H. itaobinus). Z. robusta (Fig. 1a, 2a) presented $2 \mathrm{n}=12$ and karyotype formula $4 \mathrm{M}+2 \mathrm{SM}$, and it exhibited strong interstitial DAPI+ bands in the short arms of one submetacentric pair,
Fig. 1 Mitotic metaphases of wild species. a Zephyranthes robusta, $2 \mathrm{n}=12$, DAPI+ (white)/CMA-, DAPI-/ CMA+ (yellow);

b Zephyranthes sp., $2 \mathrm{n}=12$, CMA+/DAPI-; c Z. sylvatica $2 \mathrm{n}=12$, CMA+/DAPI-; d $Z$. sylvatica $2 \mathrm{n}=18, \mathrm{CMA}+$ / DAPI-; e Z. brachyandra $2 \mathrm{n}=24+1 \mathrm{~B}$, DAPI + / CMA-, CMA+/DAPI-, f $H$. itaobinus, $2 \mathrm{n}=44+1 \mathrm{~B}$, CMA+/DAPI-. Bars $10 \mu \mathrm{m}$
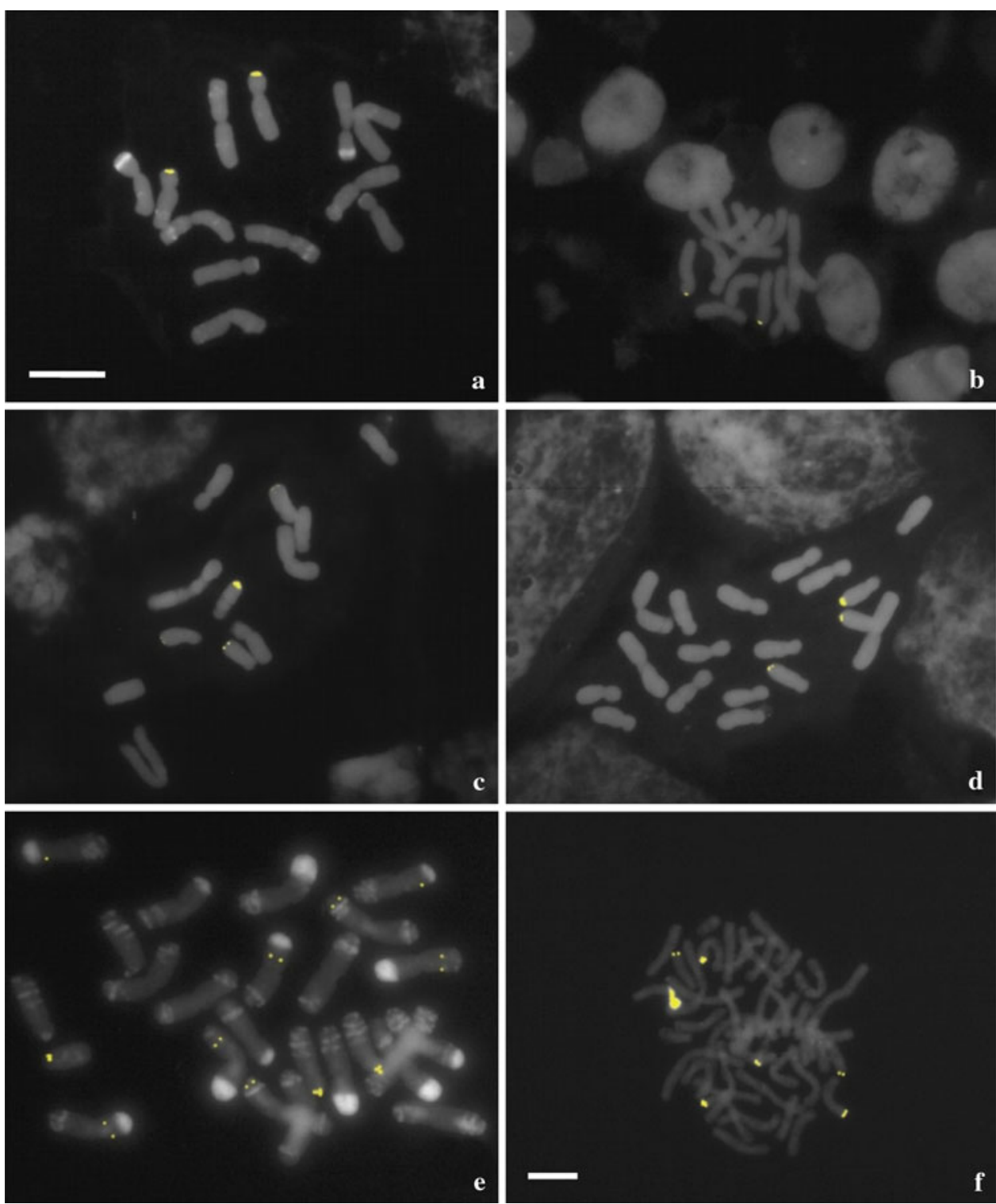
and other interstitial DAPI+ bands of varying intensity in all chromosomes except the number five chromosome pair. A strong CMA+ band was observed at the sixth chromosome pair localized in a terminal position. Zephyranthes sp., with $2 \mathrm{n}=12$ and karyotype formula $4 \mathrm{M}+1 \mathrm{SM}+$ $1 \mathrm{~A}$, showed a subterminal CMA+ heterochromatin band in the short arm of acrocentric pair (Fig. 1b). Z. sylvatica, with $2 \mathrm{n}=12$ and karyotype formula $1 \mathrm{M}+5 \mathrm{SM}$, had a stronger heteromorphic subterminal CMA+ band in the long arm of the sixth pair, plus a small CMA+ band terminal in the long arm of pair five (Fig. 1c). This same species showed a triploid cytotype with identical karyotype though formed by cracks, with a heteromorphic CMA band in the sixth crack (Figs. 1d and 2c). Z. brachyandra, with $2 \mathrm{n}=24+1 \mathrm{~B}$ and formula $4 \mathrm{M}+3 \mathrm{SM}+5 \mathrm{~A}+(1 \mathrm{~B})$, stood out by presenting a complex pattern of DAPI+ heterochromatin (Figs. 1e and 2d, f). Large subterminal bands were observed in the short arms of five acrocentric pairs and in the long arms of a large submetacentric pair. In addition to these bands, there were minor interstitial bands on both arms of pairs 1, 3, 9, 11 and 12 and in the long arms of other chromosomes. Strong CMA+ heterochromatin bands were observed on pair eight, apparently a satellite pair, and on the short arm of the B chromosome.
Small dot bands were visualized in the interstitial region of the short arms of pairs one, four, and six and in the long arm of pair five.

H. itaobinus presented $2 \mathrm{n}=44+1 \mathrm{~B}$ and karyotype formula $5 \mathrm{M}+12 \mathrm{SM}+5 \mathrm{~A}+(1 \mathrm{~B})$ and showed four pairs with subterminal CMA+ bands. In another pair a strong CMA+ band was observed in one of the homologues of the submetacentric pair, presumably a nucleolus organizer region (NOR) extended and amplified in only one of the homologous chromosomes, or heterozygous pair (Fig. 1f).

Among the cultivated species, both cytotypes were observed in $Z$. rosea, one with $2 \mathrm{n}=24$ and another with $2 \mathrm{n}=25$ and formulas $4 \mathrm{M}+7 \mathrm{SM}+1 \mathrm{~A}$ and $4 \mathrm{M}+$ $7 \mathrm{SM}+1 \mathrm{~A}+(1 \mathrm{M})$. In both cytotypes from different populations, a CMA band was observed at the short arm terminals of pairs five and six (Fig. 3a, b). Z. grandiflora, with $2 \mathrm{n}=24$ and karyotype formula $2 \mathrm{M}+5 \mathrm{SM}+5 \mathrm{~A}$, showed CMA bands at the long arm terminals of pairs three and four (Fig. 3e, f). In Z candida with $2 \mathrm{n}=38$ and karyotype formula $9 \mathrm{M}+5 \mathrm{SM}+5 \mathrm{~A}, \mathrm{CMA}+$ heterochromatin blocks were observed on the long arms of five metacentric pairs and in the short arm of a submetacentric pair, in addition to a terminal band on the long arm of one of the homologues of a larger submetacentric pair (Fig. 3g, h).
Fig. 2 Karyograms of Zephyranthes robusta. a $2 \mathrm{n}=12$, DAPI+/CMA-, DAPI-/CMA+; Z. sylvatica, $2 \mathrm{n}=12 b$ CMA+/DAPI-; Z. sylvatica, $2 \mathrm{n}=18 c \mathrm{CMA}+1$ DAPI - and Z. brachyandra with $2 \mathrm{n}=24+1 \mathrm{~B} d, f$ DAPI+/CMA-, CMA+/ DAPI-. Bar $10 \mu \mathrm{m}$

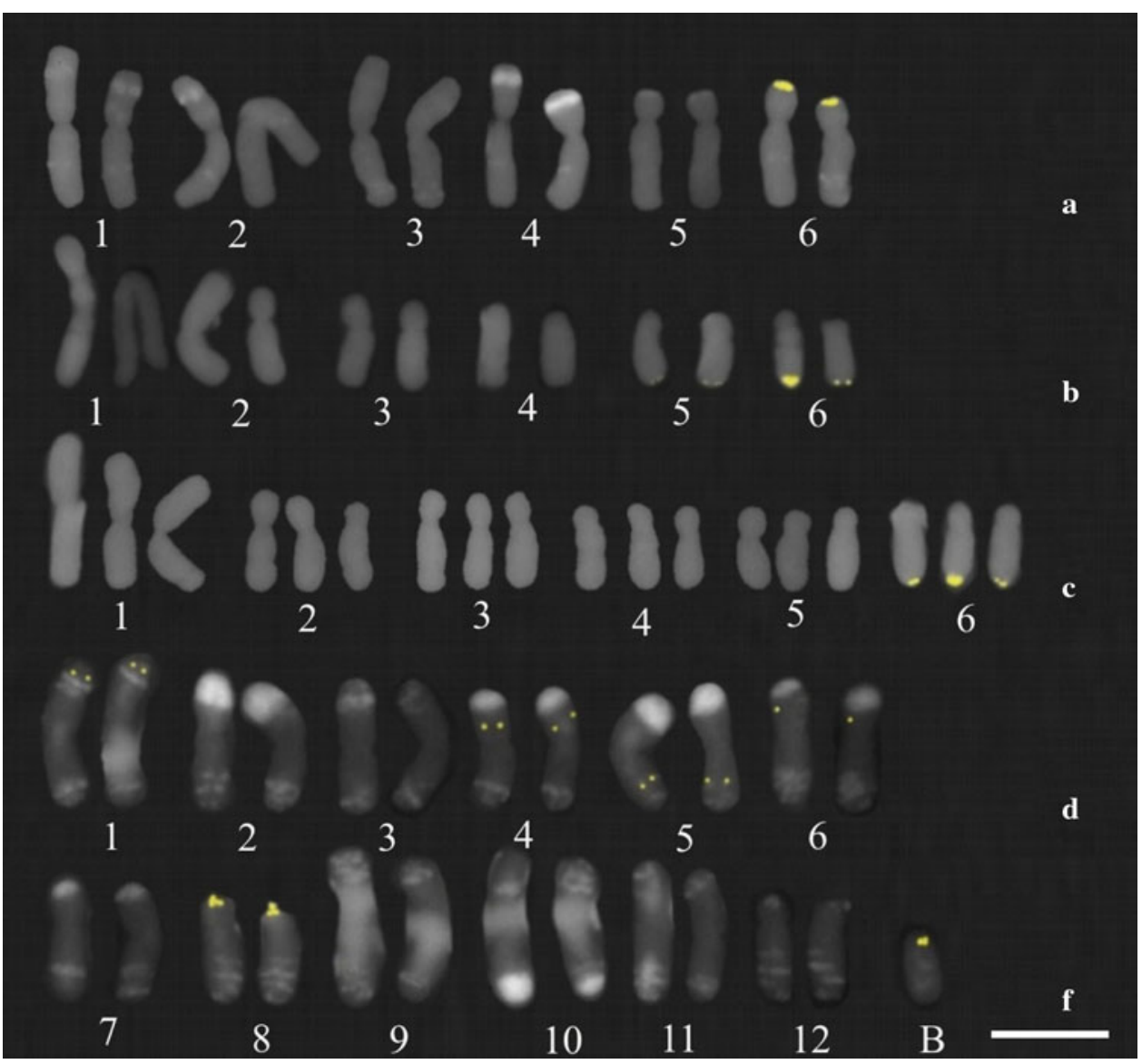


Fig. 3 Mitotic metaphases and ideograms of cultivated species. a, b Zephyranthes rosea $2 \mathrm{n}=24$, from Areia/PB population; c, $\mathbf{d}$ Z. rosea from Belém/PA population with $2 \mathrm{n}=24 ; \mathbf{e}, \mathbf{f} Z$. grandiflora, $2 \mathrm{n}=24$, and $\mathbf{g}, \mathbf{h} Z$. candida, $2 \mathrm{n}=38$. Black markers on the ideograms indicate CMA+ bands. Bar $10 \mu \mathrm{m}$
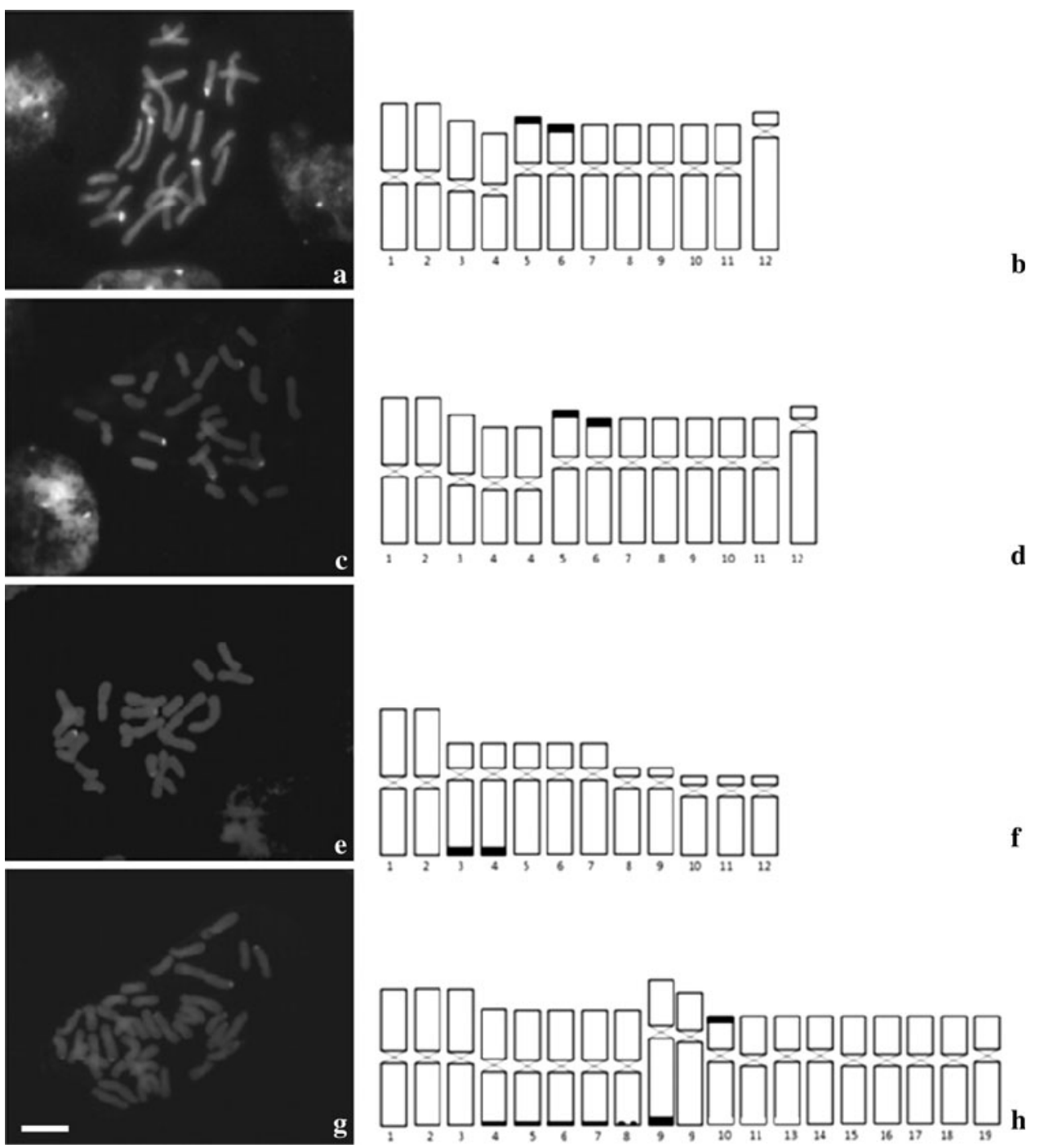

\section{Discussion}

The genus Zephyranthes is considered quite closely related to the genus Habranthus, and they have often been considered congeneric (Dutilh, personal communication). In phylogenetic analysis for the Amaryllidaceae from the Americas (Meerow et al. 2000a), it was demonstrated that Zephyranthes is polyphyletic and that some species from the southern United States and Mexico are sisters of Habranthus, reinforcing the idea of proximity of some species of both genera. In this analysis, Z. brachyandra and Z. robusta, which are sometimes included in Habranthus, differed by having AT-rich bands. However, H. itaobinus (Ravena 1999) exhibited only CMA bands similar to other species of Zephyrathes, suggesting that this characteristic is variable in the genus. Both genera are distinguished morphologically by presenting flowers and stamens declined (Oliveira 2006). Bentham (1883) considered all Habranthus species to be Zephyranthes synonyms, which is also reinforced based on overlapping anatomical and morphological characters (Arroyo 1981). However, H. itaobinus cannot be included in Zephyranthes, since it has not been recombined yet.

The genera Zephyranthes and Habranthus are known to have a wide variation in the number of chromosomes, often observed in a single population. Species such as Z. grandiflora (Greizerstein and Naranjo 1987) and Z. sylvatica in northeast Brazil (Felix et al. 2008) sometimes exhibit intrapopulation numerical variation. This variability also seems to occur in the chromosome structure. In Z. sylvat$i c a$, the only triploid individual examined showed a different CMA band pattern than that expected for a supposed self-triploid. In this case, it seems there has been loss of a CMA band in the establishment of this individual in the field. Similarly, Z. rosea also showed numerical variation among different populations with $2 \mathrm{n}=24$ and $2 \mathrm{n}=25$.

Among species with $2 \mathrm{n}=12, Z$. robusta differed from other species by presenting a set of DAPI+ 
heterochromatin blocks widely distributed across all chromosomes. Although it is the only species known from Argentina with $2 \mathrm{n}=12$, this pattern of heterochromatic bands clearly differed from other species from northern and northeastern Brazil that have this chromosome number, as they were devoid of AT-rich heterochromatin. Among Brazilian species with $2 \mathrm{n}=12, Z$. sylvatica showed a CMA band pattern distinct from Zephyranthes sp., species that are quite related morphologically, with two pairs with subterminal bands on the long arms in the former and only one pair on the short arm of the acrocentric pair in the latter. For the species group with $2 \mathrm{n}=12$, the CMA+ heterochromatin distribution seems to be a good indicator of the ploidy level. This is remarkable in Zephyranthes sp. and Z. robusta with only two CMA+ blocks. On the other hand, Z. sylvatica had four CMA blocks of which one pair was strongly heteromorphic, displaying a large block and another small one, suggesting there have been unequal translocations involving these heterochromatin regions.

The other Zephyranthes species can be divided into two groups based on chromosome number: one group with $2 n=24$ (Z. brachyandra, Z. rosea, and Z. grandiflora) and another one with $2 \mathrm{n}=38$ ( $Z$. candida). In the first group, $Z$. brachyandra, an Argentinean species, differed from other species by having DAPI+ heterochromatin spread among all chromosomes of the complement forming subterminal and interstitial bands. Among the species examined in this sample, only $Z$. robusta with $2 \mathrm{n}=12$ showed DAPI bands in the interstitial regions in most chromosomes of the complement. Both species occur in Argentina and the existence of DAPI bands in both suggests that they may be phylogenetically related. In this case, Z. brachyandra would be a tetraploid that would have extended additional DAPI+ blocks through structural changes. However, $Z$. brachyandra was distinguished from all species analyzed by presenting small punctate interstitial CMA blocks in several chromosomes of the complement, in addition to terminal blocks of the heterochromatic NOR, which was also observed in the supernumerary chromosome. The other two species with $2 \mathrm{n}=24$ showed no DAPI bands and both had only two pairs with CMA bands, which were probably retained from a diploid ancestral stock with $x=6$. These blocks were located on the short arm of $Z$. rosea and in the long arm of two submetacentric pairs of $Z$. grandiflora. On the other hand, Z. candida, which probably constitutes a hexaploid based on $x_{1}=6$, presented CMA blocks that were translocated to other chromosomes, but preferentially retained the location on the chromosome long arm in at least five metacentric and one submetacentric pair. Blocks observed in the short arms of a metacentric pair and in a single chromosome of the larger heteromorphic submetacentric pair may be the result of translocations and inversions that occurred during this species' evolution. Z. candida is a remarkable species in terms of its variation in chromosome numbers (Daviña 2001), and the heteromorphism of heterochromatic blocks and chromosomal size is probably related to rearrangements that can also result in numerical changes.

H. itaobinus, with $2 \mathrm{n}=44+1 \mathrm{~B}$, had the largest number of chromosomes in this sample and probably represents a hexaploid based on $x_{1}=7$ with diploid gain of one chromosome pair and a small metacentric B. The species had seven $\mathrm{CMA}+$ blocks that were heteromorphic for an extensive expansion of the NOR (CMA+) on one of the homologous chromosomes of the satellite pair and also the loss of a CMA block in a homologue of another chromosome pair. This pattern of CMA bands did not correspond to the number of bands expected for a hexaploid species, indicating that it is going through a diploidization process. In this process a reduction in chromosome number can occur, especially in species currently diploided that had a large genomic size reduction, as demonstrated in Arabidopsis thaliana and other Brassicaceae (Lysaker et al. 2006). Other species have undergone a massive silencing and loss of redundant gene loci but suffered no significant reduction in genome size and chromosome number (Adams and Wendel 2005). Possibly, a similar process may be underway in $H$. itaobinus, where the loss of several duplicated CMA + heterochromatin loci can clearly be observed. These blocks often correspond to 45S rDNA loci and are located in the terminals of the short chromosome arms (Guerra 2000), as observed in the genus Manihot (Carvalho and Guerra 2002).

The species studied in this work presented some trends in heterochromatin evolution, more easily observable in the species with $2 \mathrm{n}=24$, where CMA blocks always corresponded to the tetraploid level. A similar trend was observed in diploid species with $2 \mathrm{n}=12$, which always presented with a CMA block in a chromosome pair, except Z. sylvatica where there was a possible translocation of a small CMA block to another chromosome pair that was not observed in the triploid cytotype. This pattern was useful in separating Z. sylvatica from the related Zephyranthes sp., which showed a different number and distribution of CMA+ heterochromatin blocks. Two other species (Z. robusta and Z. brachyandra) stood out in terms of the occurrence of subterminal and interstitial DAPI bands, suggesting an ancestor with $\mathrm{x}=12$, similar to $Z$. robusta. $H$. itaobinus and $Z$. candida were distinguished by having marked heteromorphism in their CMA+ heterochromatin distribution.

Acknowledgments We thank Prof. Marcelo Guerra of the Botany Department of Federal University of Pernambuco for allowing the use of the DMRB photomicroscope to capture and analyze chromosomes. 


\section{References}

Adams KL, Wendel JF (2005) Polyploidy and genome evolution in plants. Curr Opin Plant Biol 8:135-141

Arroyo SC (1981) Systematic, anatomical studies on Amaryllidaceae, including morphological cytological and phytogeographical considerations. PhD Thesis, Department of Botany, University of Reading, Reading

Bentham G (1883) Amaryllidaceae. In: Bentham G, Hooker JD (eds) Genera plantarum 3:710-740

Bhattacharyya NK (1972) Chromosome inconstancy in Zephyranthes mesochloa Baker. Cytologia 37:423-433

Carvalho R, Guerra M (2002) Cytogenetics of Manihot esculenta Crantz (Cassava) and eight related species. Hereditas 136:159-168

Daviña JR (2001) Estudios citogeneticos en algunos generos argentinos de Amaryllidaceae. PhD Thesis, Universidade Nacional de Córdoba, Córdoba

Dutilh JHA (2005) Ornamental bulbous plants of Brazil. Acta Hortic 683:37-42

Felix WJP, Almeida A, Melo NF, Felix LP (2007) Citogenética de duas espécies de Zephyranthes Herb. (Amaryllidaceae-Hipeastreae) cultivadas. Rev Bras Bioci 5:294-296

Felix WJP, Dutilh JHA, Melo NF, Almeida A, Felix LP (2008) Intrapopulational chromosome number variation in Zephyranthes sylvatica Baker (Amaryllidaceae: Hippeastreae) from northeast Brazil. Rev Bras Bot 32:371-375

Flory WS, Smith GL (1980) High chromosome number in several Zephyrantheae taxa. Pl Life 36:63-72

Greizerstein EJ, Naranjo CA (1987) Estudios cromosomicos en especies de Zephyranthes (Amaryllidaceae). Darwiniana 29:169-186
Guerra M (2000) Patterns of heterochromatin distribution in plant chromosomes. Genet Molec Biol 23:1029-1041

Hutchinson J (1959) The families of flowering plants. Clarendon Press, Oxford, p 792

Judd WS, Campbell CS, Kellogg EA, Stevens PF (1999) Plant systematics: a phylogenetic approach. Sinauer Associates, Sunderland

Lysaker MA, Berr A, Pecinka A, Schmidt R, Mcbreen K, Schubert I (2006) Mechanisms of chromosome number reduction in Arabidopsis thaliana and related Brassicaceae species. Proc Nat Acad Sci USA 103:5224-5229

Meerow AW, Fay MF, Chase MW, Guy CL, Li Q, Snijman D, Yang S (2000a) Phylogeny of Amaryllidaceae: molecules and morphology. In: Wilson KL, Morrison DA (eds) Monocots: systematics and evolution. CSIRO, Collingwood, pp 372-386

Meerow AW, Guy CL, Li Q, Yang S (2000b) Phylogeny of the American Amaryllidaceae based on nrDNA ITS sequences. Syst Bot 25:708-726

Meerow AW, Reveal JL, Snijman DA, Dutilh J (2007) Proposal to conserve the name Amaryllidaceae against Alliaceae, a "superconservation" proposal. Taxon 56:1300-1301

Oliveira RS (2006) Flora da Cadeia do Espinhaço: Zephyranthes Herb. \& Habranthus Herb. (Amaryllidaceae). Master's Dissertation, Universidade de São Paulo, São Paulo

Raina SN, Khoshoo TN (1971) Cytogenetics of tropical bulbous ornamentals VI: chromosomal polymorphism in cultivated Zephyranthes. Caryologia 2:217-227

Ravena PF (1999) New species of Zephyranthes and Habranthus (Amaryllidaceae). Onira 3:54-59

Schweizer D (1976) Reverse fluorescent chromosome-banding with chromomycin and DAPI. Chromosoma 58:307-324 